\title{
9.9 MIDDLE ATMOSPHERE MEASUREMENTS OF SMALL-SCALE ELECTRON DENSITY IRREGULARITIES AND ION PROPERTIES DURING THE MAC/EPSILON CAMPAIGN
}

\author{
S. P. Blood, J. D. Mitchell, and C. L. Croskey \\ Communications and Space Sciences Laboratory \\ Department of Electrical Engineering, The Pennsylvania State University \\ University Park, PA 16802
}

Rocket payloads designed to measure small-scale electron density irregularities and ion properties in the middle atmosphere were flown with each of the three main salvos of the MAC/Epsilon campaign conducted at the Andoya Rocket Range, Norway, during October to November 1987. Fixed-bias, hemispheric nose tip probes measured small-scale electron density irregularities, indicative of neutral air turbulence, during the rocket's ascent; and subsequently, parachute-borne Gerdien condensers measured the region's polar electrical conductivity, ion mobility and density. One rocket was launched during daylight (October 15, 1052:20 UT), and the other two launches occurred at night (October 21, 2134 UT; November $12,0021: 40$ UT) under moderately disturbed conditions which enhanced the detection and measurement of turbulence structures. A preliminary analysis of the real-time data displays indicates the presence of small-scale electron density irregularities in the altitude range of 60 to $90 \mathrm{~km}$. Ongoing data reduction will determine turbulence parameters and also the region's electrical properties below $90 \mathrm{~km}$.

TABLE 1 MAC/Epsilon Campaign--Penn State Experiments

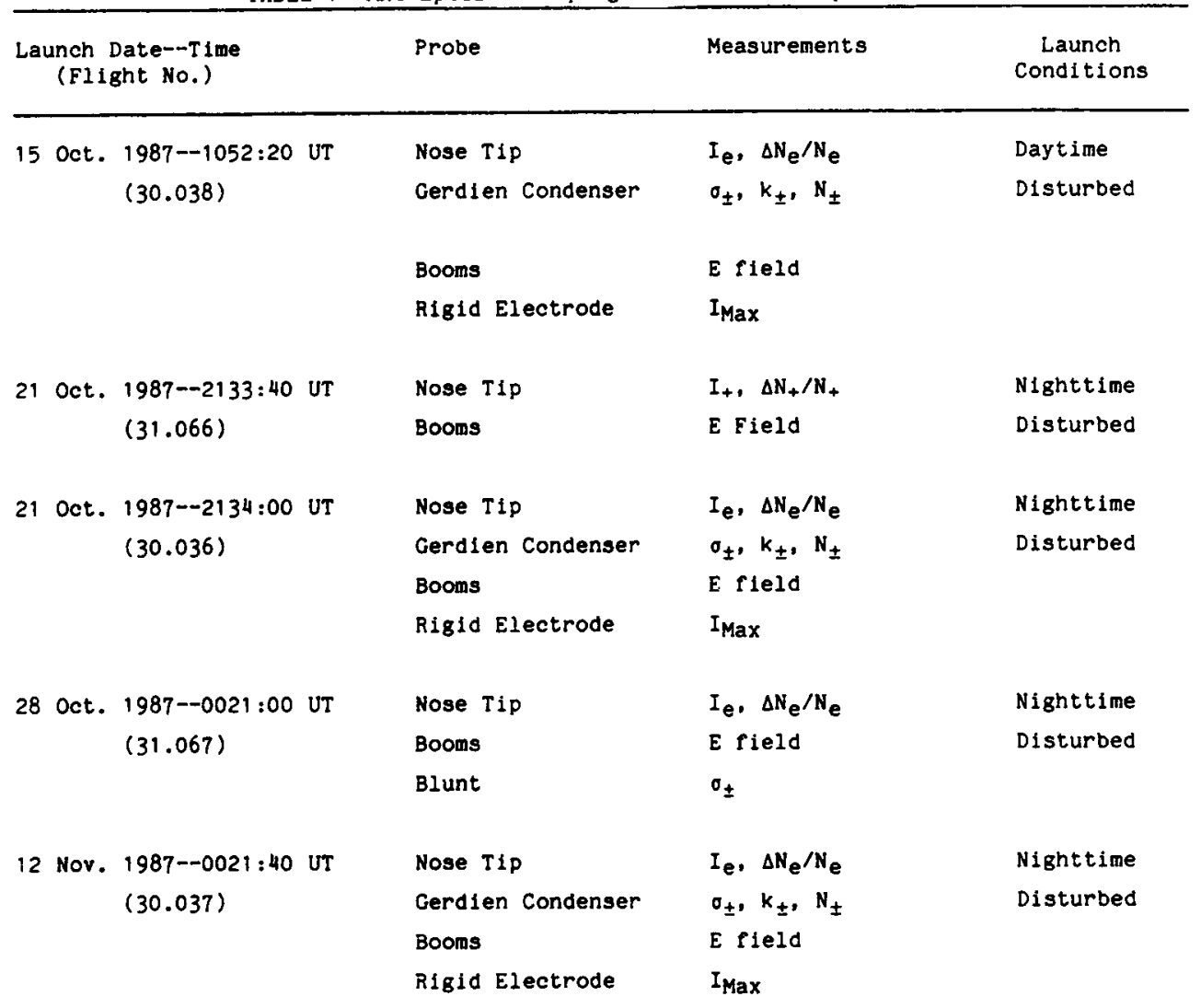




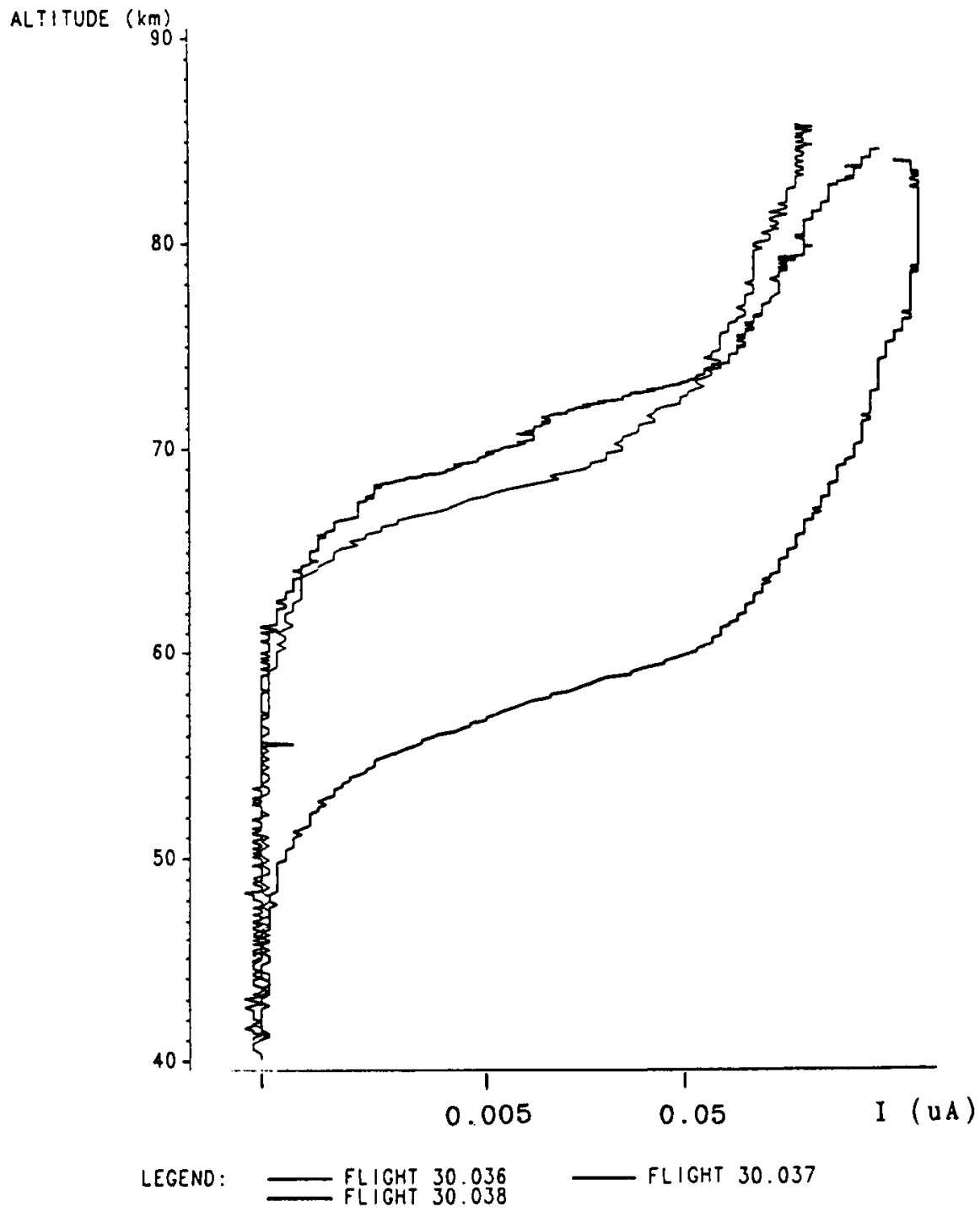

Figure 1. Nose tip probe electron current measurements for flights $30.036,30.037$ and 30.038. The different currents, for the same altitude, are indicative of relative electron concentrations. The electron number densities are the largest for the daytime flight 30.038 (salvo 1). In comparing the two nighttime current profiles, the electron concentration for salvo 2 (flight 30.036) was larger below $73 \mathrm{~km}$ and smaller above that altitude. Large scale $(21 \mathrm{~km})$ wave-like structures are noticeable in the electron current measurements, particularly at altitudes above $70 \mathrm{~km}$. 


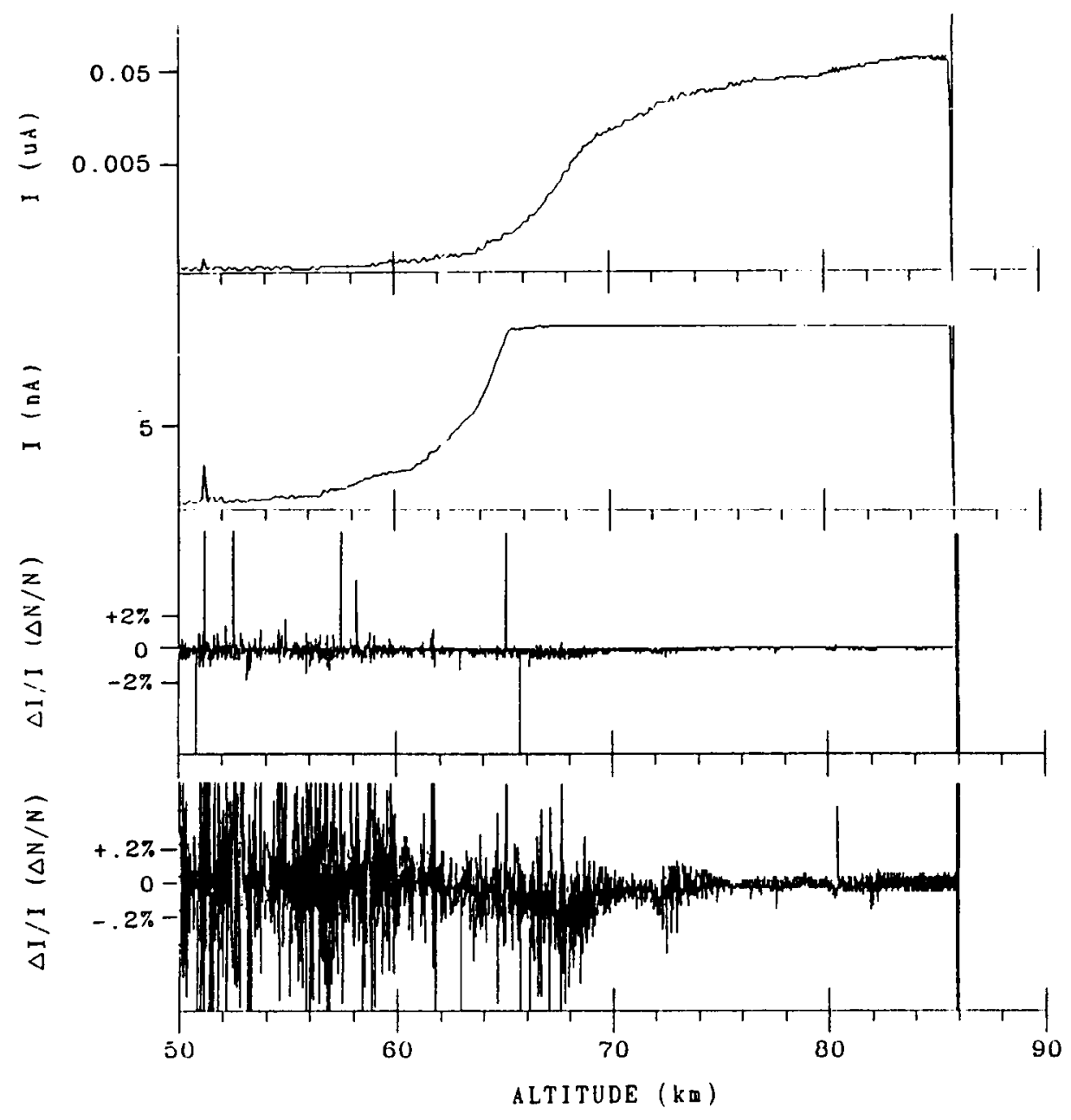

Figure 2. Nose tip prove dc and ac (amplified) electron current measurements for flight 30.036 (salvo 2). The dc electron current measurements (upper two panels) indicate the presence of free electrons at altitudes above approximately $64 \mathrm{~km}$. Noticeable ac current variations (electron density fluctuations) at $68 \mathrm{~km}$ and $72-74 \mathrm{~km}$ indicate possible regions of small-scale turbulence. A power density spectrum for the small-scale electron density irregularities at $74 \mathrm{~km}$ showed a slope of $-5 / 3$ for frequencies of $10-200 \mathrm{~Hz}$, indicating turbulence in the inertial subrange. A spectral index of -7 at higher frequencies, indicative of the viscuous range, also was determined. 


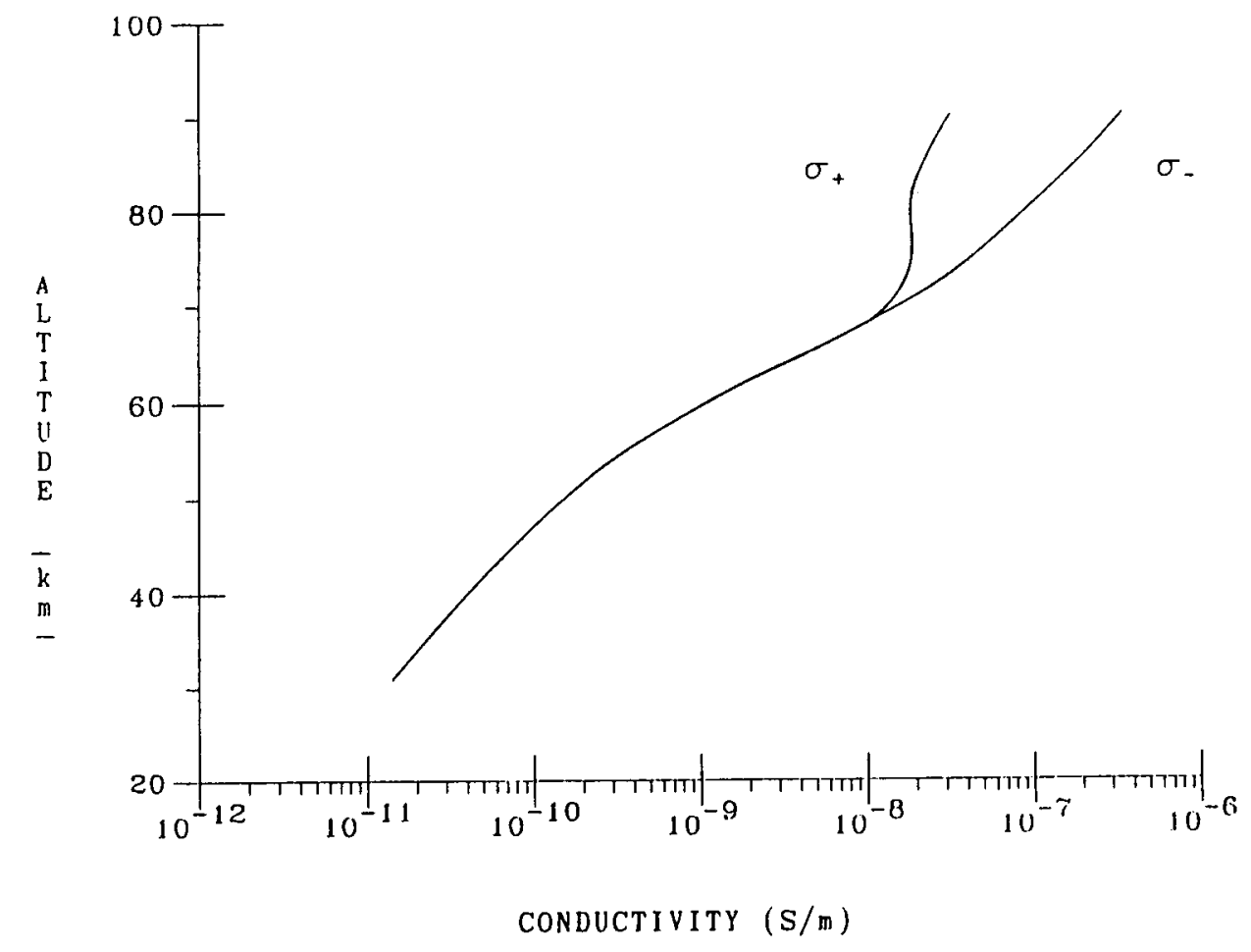

Figure 3. Profiles of positive and negative electrical conductivity obtained for flight 30.036 (salvo 2) by a parachute-borne Gerdien condenser. The altitude dependence for conductivity indicates the presence of auroral ionization sources above approximately $50 \mathrm{~km}$ (supported by the energy deposition measurements of Goldberg et al.) The relatively larger negative conductivity values above $65-70 \mathrm{~km}$ signifies the region where free electrons are present, which is consistent with the nose tip probe data of Figures 1 and 2. 